\title{
ANAESTHETIC EXPERIENCE USING A STANDARD TECHNIQUE FOR LARYNGEAL SURGERY IN INFANTS AND CHILDREN
}

\author{
M.G. Kennedy, H.M. Chinyanga and D.J. Steward
}

\begin{abstract}
A 12 year review is presented of 1922 anaesthetic experiences on 285 patients presenting for microlaryngeal operations at the Hospital For Sick Children, Toronto. The lesions treated were laryngeal growths, 198 cases (69.5 per cent); subglottic stenosis, 81 cases ( 28.4 per cent); and posterior laryngeal cleft, 6 cases $(2.1$ per cent). The anaesthetic technique consisted of topical analgesia with lidocaine spray $\left(3 \mathrm{mg} \cdot \mathrm{kg}^{-1}\right)$ and pharyngeal insufflation of halothane and methoxyflurane both 1-1.5 per cent in oxygen through a special channel in the blade of a Jako Pilling microlaryngoscope in spontancously brcathing patients.

Arterial blood gases sampled after 15 and 40 minutes of anaesthesia showed $\mathrm{Pa}_{\mathrm{CO}_{2}}=6.29 \pm$ $0.31 \mathrm{kPa}\left(47.1 \pm 2.39\right.$ torr) and $6.44 \pm 0.16 \mathrm{kPa}\left(48.1 \pm 1.22\right.$ torr) $; \mathrm{Pa}_{\mathrm{O}_{2}}=29.06 \pm 4.33 \mathrm{kPa}$ (218 \pm 32.5 torr) and $37.06 \pm 4.82 \mathrm{kPa}(278 \pm 36.2$ torr) respectively. Surgical exposure of the Jarynx was good allowing for a shorter operative time with minimal perioperative complications, in only 94 ( 4.89 per cent) of the 1922 anaesthetics.
\end{abstract}

Key Words: Anaesthetic Techniques, insufflation; Surgery, laryngeal, infants and children.

ANAESTHESIA FOR CHILDREN undergoing microlaryngoscopy or laryngeal microsurgery under general anaesthesia poses special problems for both anaesthetist and surgeon. ' Effective airway control, adequate ventilation, good surgical access and prevention of aspiration are of prime importance.

We present our experience with a standard anaesthetic technique at The Hospital For Sick Children, Toronto, over a period of twelve years (1968-1979).

\section{Materials and Methods}

At The Hospital For Sick Children in Toronto, between 1968 and 1979, 285 children and eight adults were given 1922 anaesthetics for operations on the larynx. Many patients required repeated procedures. One hundred and ninety (66 per cent) of the patients were males. The pathology of the lesions requiring operation is shown in Table I.

Of the 81 patients with subglottic stenosis, 32 (39.5 per cent) were two years of age or less. The

M.G. Kennedy, M.B., Ch.B., R-3 (1979); H.M. Chinyanga, M.D., F.R.C.P.(C), Staff Anaesthetist; D.J. Steward, M.B., B.S., F.R.C.P.(C), Anaesthetistin-Chief; Department of Anaesthesia, The Hospital For Sick Children, Toronto, Ontario, Canada.

Reprint Requests to: Dr. H.M. Chinyanga, Department of Anaesthesia, The Hospital For Sick Children, 555 University Avenue, Toronto, Ontario M5G IX8.

Can. Anaesth. Soc. J., vol. 28, no. 6, November 1981 aetiology of the subglottic stenosis is summarized in Table II. The majority of patients with subglottic stenosis (65.4 per cent) were treated by dilating the stenosis with a rigid bronchoscope. Twenty patients (24.6 per cent) had the lesions resected by either laser or forceps. The remainder, except for one case, had a combination of resection and dilatation. Three patients in this series had laryngotracheoplasty. ${ }^{2}$

Eight of the 198 patients with laryngeal growths were adults. The nature of the lesions is shown in Table III.

TABLE I

\begin{tabular}{lcc}
\hline \multicolumn{1}{c}{ Lesions } & Number & Per Cent \\
\hline Laryngeal Growths & 198 & 69.5 \\
Subglottic Stenosis & 81 & 28.4 \\
Posterior Laryngeal Cleft & 6 & 2.1 \\
Total Number of Cases & 285 & \\
Total Number of Anaesthetics & 1922 & \\
\hline
\end{tabular}

TABLE II

Lesions Causing Subglottic Stenosis

\begin{tabular}{lcc}
\hline \multicolumn{1}{c}{ Lesions } & Number & Per Cent \\
\hline Congenital Subglottic Stenosis & 68 & 83.95 \\
Haemangioma & 8 & 9.87 \\
Granuloma & 2 & 2.46 \\
Webs & 2 & 2.46 \\
Cysts & 1 & 1.23 \\
Total Number of Cases & $\overline{81}$ & \\
\hline
\end{tabular}


TABLE III

LARYNGEAL GROWTHS

\begin{tabular}{lcr}
\hline \hline \multicolumn{1}{c}{ Lesions } & Number & Per Cent \\
\hline Nodules & 104 & 52.50 \\
Papillomata & 48 & 24.24 \\
Polyps & 19 & 9.50 \\
Haemangiomata & 10 & 4.50 \\
Webs & 9 & 4.50 \\
Cysts & 5 & 2.50 \\
Granuloma & 3 & 1.50 \\
Total Number of Patients & 198 & \\
\hline
\end{tabular}

Since the introduction of carbon dioxide laser equipment in this hospital in 1975, it has been used to treat 72 patients presenting for microlaryngeal surgery (Table IV). The youngest patient for laser surgery of the larynx was two months old and 38 (52.7 per cent) were less than ten years of age.

\section{The Anaesthetic Technique}

The special problems for the anaesthetist during operations on the larynx in children are maintenance of an adequate airway and ventilation, provision of unobstructed surgical access of the larynx, and prevention of laryngospasm caused by manipulation within the airway, inadequate topical analgesia, or inadequate depth of anaesthesia.

Our anaesthetic technique has been described in detail in an earlier paper. ${ }^{2}$ It includes:

1. Pharyngeal insufflation of oxygen, halothane and methoxyflurane (both $1-1.5$ per cent) to produce a moderate depth of anaesthesia. $\mathrm{Pa}$ tients breathe spontaneously.

2. Topical analgesia of the larynx and trachea with lidocaine ( $3 \mathrm{mg} \cdot \mathrm{kg}^{-1}$ maximum dose).

3. Delivery of the anaesthetic gases to the pharynx through a special channel incorporated into the Jako Pilling Suspension microlaryngoscope (Figure 1).

TABLE IV

$\mathrm{CO}_{2}$-Laser Microlaryngeal TreatMenT 1975-1979

\begin{tabular}{lcc}
\hline \multicolumn{1}{c}{ Lesions } & Number & Per Cent \\
\hline Papillomata & 20 & 28.57 \\
Nodules & 15 & 20.83 \\
Polyps & 12 & 16.66 \\
Cysts & & \\
Haemangiomata & & \\
Hypertrophic Lesions of the & & \\
$\quad$ Cords & 12 & 16.16 \\
Subglottic Stenosis With Polyps & 8 & 11.11 \\
Subglottic Stenosis Only & 5 & 6.94 \\
Laryngeal Webs & $\overline{72}$ & \\
Total Number of Cases & & \\
\hline
\end{tabular}

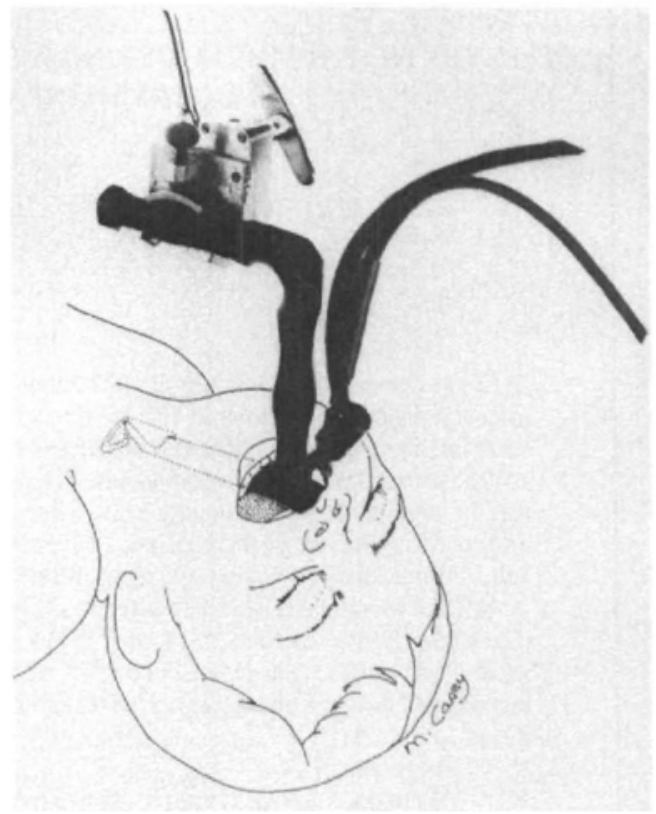

FIGURE 1 Suspension Jako Pilling microlaryngoscope in position showing fiberoptic light source cable, anaesthetic gas port and view of the larynx.

Inhalation induction was carried out in the majority of patients. In a few patients with isolated lesions of the larynx, where the danger of total airway obstruction was minimal, anaesthesia was induced with a sleep dose of thiopentone (2-5 mg $\cdot \mathrm{kg}^{-1}$ ). Atropine $0.02 \mathrm{mg} \cdot \mathrm{kg}^{-1}$ was administered intravenously at induction. An endoscopist was always in attendance, ready to introduce a rigid bronchoscope should total airway obstruction occur during induction or emergence from anaesthesia. The vital signs were monitored closely throughout the procedure, using a precordial stethoscope, blood pressure cuff, Doppler pulse monitor, ${ }^{*}$ and electrocardiogram.

The ventilating bronchoscope was used for the management of subglottic stenosis (Figure 2). In patients with tracheostomies, anaesthesia was induced and maintained with halothane and methoxyflurane in oxygen through the tracheostomy tube or bronchoscope, depending on which part of the larynx the operation was to be carried out.

When the laser was used, personnel in the operating room wore ordinary plain glasses to protect the cornea from damage by the laser beam should it accidentally deflect from shiny metal surfaces during the operation. To protect

\footnotetext{
*Parks Electronics
} 


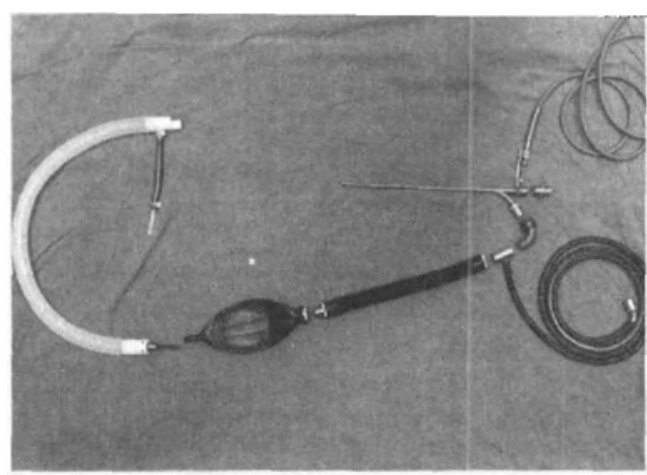

FIGURE 2 Ventilating bronchoscope setup showing rigid bronchoscope with its fiberoptic cable light source, Jackson-Rees $T$ piece, corrugated tubing and reservoir bag. Flowerdew coaxial scavenging device.

the patient, eyelids were shut and wet towels were placed around the mouth and face.

To examine the adequacy of ventilation during anaesthesia using this technique, arterial blood gas samples were taken for analysis at 15 and 40 minutes after the start of anaesthesia.

After operation, the surgical instruments (bronchoscope or microlaryngoscope) were removed and the patients were allowed to wake up breathing oxygen 40 per cent in air by a Puritan mask, hood or croupette. Here they were observed for one to two hours and discharged to the ward to continue breathing humidified oxygen in air for another six hours.

\section{RESULTS}

The number of uneventful anaesthetics was 1828 ( 95.11 per cent) while 94 (4.89 per cent) were

TABLE V

\begin{tabular}{lrr}
\hline & & Per \\
& Number & Cent \\
\hline Peri-operative A naesthetic Complications & \\
Total number of anaesthetics & 1922 & \\
Anaesthetics without complications & 1828 & 95.11 \\
Anaesthetics with complications & 94 & 4.89 \\
Complicarions & & \\
Obstructed airway & 43 & 2.20 \\
Stridor & 26 & 1.46 \\
Bronchospasm & 9 & 0.46 \\
Vomiting & 4 & 0.20 \\
Cardiac Arrest & 3 & 0.15 \\
Cyanosis & 3 & 0.20 \\
Aspiration & 2 & 0.10 \\
Laryngospasm & 1 & 0.05 \\
Secretions & 1 & 0.05 \\
Convulsion & 1 & 0.05 \\
Tooth dislodged & 1 & 0.05 \\
\hline
\end{tabular}

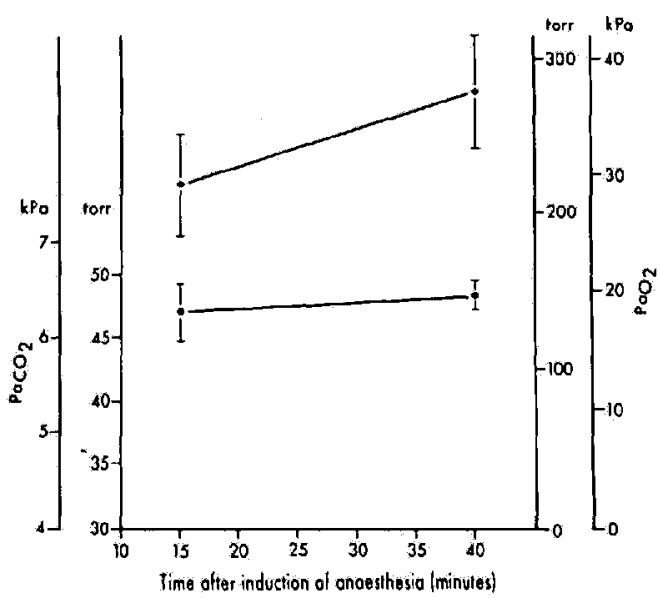

Figure 3 Means and standard error of means of $\mathrm{Pa}_{\mathrm{CO}_{2}}$ and $\mathrm{Pa}_{\mathrm{O}_{2}} 15$ and 40 minutes after induction of anaesthesia.

associated with perioperative complications. Complications are listed in Table $\mathrm{V}$.

The results and standard errors of the arterial blood gas samples taken during the surgical procedures are shown in Table VI, and Figure 3. The results show excellent oxygenation and a moderate degree of hypercapnia. There was no significant difference in the values of the arterial blood gases taken at 15 minutes and 40 minutes during spontaneous ventilation with pharyngeal insufflation.

\section{Discussion}

Many other successful anaesthetic techniques have been described for laryngeal surgery. Benjamin and Lines (1972) used a technique involving spontaneous ventilation and pharyngeal insufflation of anaesthetic gases through a nasopharyngeal tube. ${ }^{3}$ This permitted clear access to the larynx.

In 1973 Lines described a technique for adults in which topical anaesthesia was combined with deep halothane anaesthesia delivered through a long cuffed tracheal tube of small diameter (3-5 $\mathrm{mm}$ I.D.). Respiration was either spontaneous or controlled with the aid of a muscle relaxant. ${ }^{4}$ The tube was placed through the posterior part of the larynx but could be moved to allow access to other areas of the glottis. Pollard described a specially tapered tube $10 \mathrm{~mm} \mathrm{I}$.D. at the machine end and $5-6 \mathrm{~mm}$ at the patient end for use in this technique.s The bulkiness of the large machine end made this tube unacceptable in small children.

Anaesthesia without a tracheal tube was 
TABLE VI

Arterial Blood Gases During Anaesthesia by Pharyngeal Insufflation

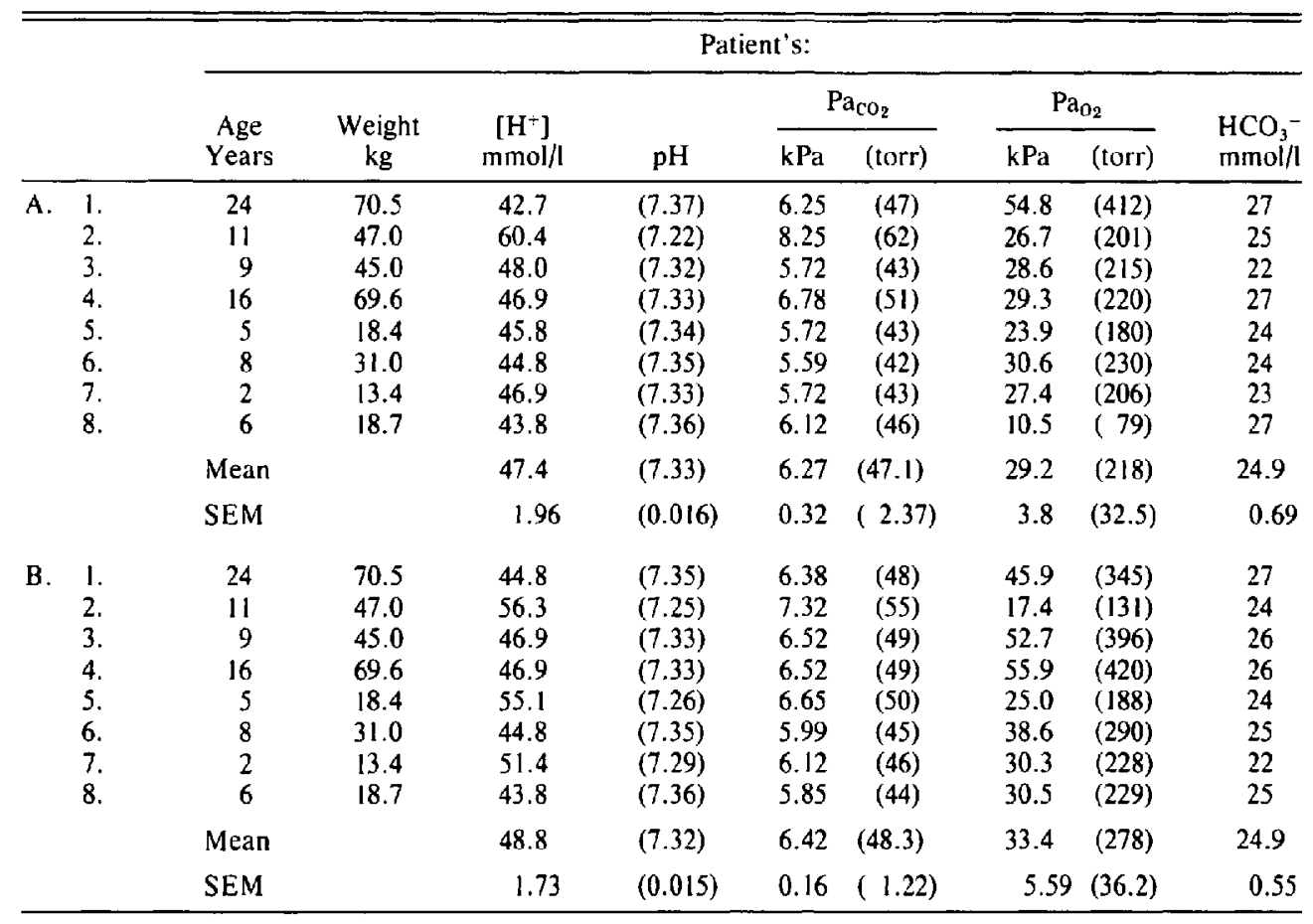

Fresh Gas Flow Rates: 10 Litres/minute; $\mathrm{Fl}_{\mathrm{O}_{2}}: 1.0$; Time after induction of anaesthesia: A - 15 minutes, $\mathrm{B}-40$ minutes.

achieved by Lines by incorporating a long wide bore needle into a channel at the side of the self-retaining laryngoscope originally equipped with a light source. ${ }^{4}$ Anaesthetic gases insufflated through the needle were delivered very close to the laryngeal aperture, thus diminishing leakage and facilitating adequate depths of anaesthesia.

Brown (1970) described a technique for microlaryngeal surgery and bronchoscopy in children which utilized the anaesthetic agent gammahydroxybutrate and topical analgesia. ${ }^{6}$ It was reported to provide good jaw relaxation without the use of muscle relaxants, so that the larynx could be visualized with the patient breathing adequately. The possibility of vomiting and the hazardous combination of prolonged unconsciousness and anaesthetized larynx make this technique dangerous in inexperienced hands.

In a series of 150 cases, Gordon and Sellars described an anaesthetic technique combining halothane oxygen general anaesthesia, neuroleptanalgesia, and topical lidocaine analgesia for laryngeal microsurgery of short duration. ${ }^{7}$ The surgical procedure was carried out through a Storz laryngoscope and its Riecker chest holder, while the patient breathed air. Additional fentanyl was given to maintain anaesthesia.

Bush administered intravenous atropine and used thiopentone for induction of anaesthesia. ${ }^{8}$ Ventilation by face mask was then tested and, all being well, succinylcholine was given and the lungs were ventilated with oxygen. The larynx was then sprayed with lidocaine through a laryngoscope. Ventilation was continued with oxygen and a low concentration of halothane until spontaneous respiration returned. At this point, further laryngoscopy was undertaken and a small plastic catheter was inserted through the nose and into the trachea. Oxygen and halothane were then insufflated through the catheter which had a blowoff valve proximally in the fresh gas supply tubing. This technique allowed the surgeon a clear view and assessment of vocal cord movement was not interfered with.

Deep diethyl ether anaesthesia was a traditional method to afford ample time for operation and to produce good relaxation of the jaw. The vocal cords continue to move but laryngospasm has not been a problem. Diethyl ether has largely been abandoned because of its flammability. 
Intermittent positive pressure ventilation using the venturi principle during laryngeal surgery with the patient paralyzed has been described in infants, children, and adults. ${ }^{9,10}$ This technique permits performance of brief or prolonged delicate procedures under general anaesthesia and controlled ventilation with a Bird Mark II ventilator or any other device to interrupt the driving gas. There was no tracheal tube to obstruct the view of the entire larynx and to hinder the use of instruments. Ventilation under these conditions has been excellent with $\mathrm{PCO}_{2}=4.79-5.45 \mathrm{kPa}$ (36-4l torr). However, distension of the stomach or dissemination of debris and blood into the trachea may occur and, on rare occasions, massive fatal mediastinal emphysema has occurred. ${ }^{11,12}$

Carden's tube and mechanical ventilation have been used successfully in adults for microlaryngeal surgery. ${ }^{13.14}$ However, this method is unsuitable for small children. Even in adults the nature of the lesions treated may preclude its use. It is difficult to use during laser surgery because of its positioning, its sizes, and the need to keep its lumen at the larynx clear and open.

The problems encountered, and the solutions when the laser is used for surgery of the larynx with a tracheal tube in place have been well discussed in a number of papers. ${ }^{15,21}$ Problems include ignition of the plastic tracheal tube, puncture and decompression of the tracheal tube cuff leading to ventilatory problems, corneal injury to patient and operating room personnel as a result of accidental reflection of the laser beam from the metal surface of surgical instruments. Safety measures include wrapping the tracheal tube with either aluminum foil or wet gauze, using non-flammable anaesthetic gases, proteclive eye covers for the patient and goggles for the operating room personnel.

Our anaesthetic technique of pharyngeal insufflation with spontaneous ventilation provides excellent oxygenation with a mild respiratory acidosis which is well tolerated by children during 30 to 45 minutes of operation. This compared favourably with the results of Jacobsen over 25 minutes of manually controlled ventilation through a $4 \mathrm{~mm}$ I.D. armoured tube. Surgical access to the larynx is optimal, resulting in a faster and more accurate operation. When the laser is used, fire hazards associated with the presence of a tracheal tube are eliminated. Gastric distension and respiratory problems encountered with the use of jet ventilation anaesthetic techniques are avoided.
Repeated exposure to halothane appears to present no problems in children. We have not seen halothane hepatitis in prepubertal children. In children methoxyflurane administration results in lower free fluoride levels and thus virtual absence of nephrotoxicity. ${ }^{22.23}$ Methoxyflurane is especially suitable for anaesthesia of the larynx because of its ability to prevent laryngospasm during surgical manipulation. ${ }^{24}$

Anaesthetic complications were minimal in our series, being 4.89 per cent of 1922 anaesthetics. There were three $(0.15$ per cent) deaths which occurred within 24 hours after operation; 43 (2.2 per cent) anaesthetics were associated with some degree of airway obstruction requiring intervention.

\section{ACKNOWLEDGEMENTS}

We wish to thank Dr. Robert E. Creighton for his critical review of the manuscript, Mrs. Casey for the artwork, and Miss Sheila M. Peart for the secretarial work.

\section{REFERENCES}

1. Simpson, G.T., Healy, G.B., MCGill, T. \& Strong, M.S. Benign tumors and lesions of the larynx in children: Surgical excisions by $\mathrm{CO}_{2}$ laser. Canad. Otol. 88: 479-485 (1979).

2. Yamashita, M., Chinyanga, H.M. \& Steward, D.J. Posterior laryngeal cleft: Anaesthetic experiences. Can. Anaes. Soc. J. 26: 502-505 (1979).

3. BeNJAMIN, B. \& Lines, V. Endoscopy anaesthesia in non-effective airway obstruction in children. Anaesthesia 27: 283-291 (1972).

4. LiNes, V. Anaesthesia for laryngoscopy and microlaryngeal surgery in children. Anaesth. \& Int. Care 1: 507-511 (1973).

5. Pollard, B. Anaesthesia for laryngeal microsurgery. Anaesthesia 23: 534-542 (1968).

6. BrowN, T.C.K. Gammahydroxybutrate in paediatric anaesthesia. Aust. N.Z.J. 40: 94 (1970).

7. Gordon, M. \& Sellers, S. Anaesthesia for microsurgery of the larynx. Anaesthesia 26: 199 (197I)

8. Bush, G.H. Personal communication to V. Lines. Anaesthesia and Int. Care 1: 519 (1973).

9. LEE. S.T. A ventilating laryngoscope for inhalation anaesthesia and augmented ventilation during laryngoscopic procedures. Brit. J. Anaesth. 44: 874-878 (1972).

10. Albert, S.N. The Albert-Sanders adaptor for ventilating anaesthetized patients for microlaryngeal surgery. Brit. J. Anaesth. 43: 1098 (1971).

11. VIVORI, E. Anaesthesia for laryngoscopy. Brit. J. Anaesth. 52: 638 (1980).

12. Steward, D.J. \& Fearon, B. Anaesthesia for laryngoscopy (letter to the editor). Brit. J. Anaesth. 1981 (In press). 
13. Carden, E. \& Crutchfield, W. Anaesthesia for microsurgery of the larynx Can. Anaesth. Soc. J 20: 378-380 (1973).

14. Soder, C.M., Haight, J., Fredrickson, J.L. \& ScotT, A.A. Mechanical ventilation during laryngeal surgery: An evaluation of the Carden tube. Can. Anaesth. Soc. J. 27: 111-124 (1980).

15. Strong, M.S. \& JAko, G.J. Laser surgery in larynx, early clinical experience with continuous $\mathrm{CO}_{2}$ laser. Ann. Otol. Rhino, Laryngol. 81: 791$798(1972)$

16. Strong, M.S., Jako, Planyi \& Wallace, R.A. Laser surgery in the aero-digestive tract. American J. Surg. I26: 529-533 (1973).

17. Konchigeri, H.N. \& Shanker, M.H. Anaesthesia for intra-laryngeal laser surgery. Can. Anaesth. Soc. J. 21: 343-349 (1974).

18. Snow, J.C., Kripke, B.J., Strong, M.S., Jako, G.J. Myer, M.R. \& Vaughan, C.W. Anaesthesia for carbon dioxide laser microsurgery on the larynx and trachea. Anaesth. \& Analg. 53: 507-511 (1974).
19. Snow, J.C., Norron, M.L., Saliya, T.S. \& EsTANISLAO, A.F. Fire hazard during $\mathrm{CO}_{2}$ laser microsurgery on the larynx and trachea. Anaesth. \& Analg. 55: 146-147 (1975).

20. Patil, V., Stehlurg, L.C. \& Zauder, H.L. A modified endotracheal tube for laser microsurgery. Anaesthesiology 51: 571 (1975).

21. DeVRIES; $P . \mathrm{CO}_{2}$ laser - a fire hazard when used in upper airway. The Medical Post. Nov. 18, 2 (1980).

22. Cousins, M.J. \& Mazze, R.I. Methoxyflurane nephrotoxicity: A study of dose response in man. J.A.M.A. 225: 1611-1616 (1973).

23. Stoelting, R.J. \& Peterson, QC. Methoxyflurane anaesthesia in paediatric patients evaluation of anaesthesia metabolism and renal function. Anaesthesiology 42; 26 (1975).

24. Steward, D.J. \& Creighton, R.E. General anaesthesia for minor surgery in healthy children. Current Problems in Anaesthesia and Critical Care Medicine, Year Book Medical Publishers No. 5 (1977).

\section{RÉSUMÉ}

Au cours des 12 dernières années, 285 patients de l'hôpital Sick Children de Toronto ont été anesthésiés à 1922 reprises pour des interventions de microchirurgie laryngée. Les pathologies en cause étaient des tumeurs laryngées ( 198 cas, soit 69.5 pour cent du total), des sténoses sousglottiques ( 81 cas, soit 28.4 pour cent du total) et des tissures laryngées postérieures (6 cas, soit 2.1 pour cent). La technique d'anesthésie consistait en une nébulisation topique de lidocaine (dose maxima $=3 \mathrm{mg} \cdot \mathrm{kg}^{-1}$ ) et une insufflation (en ventilation spontanée) de méthoxyflurane, d'halothane (les deux à des concentrations de 1 à 1.5 pour cent) et d'oxygène par un tube latéral incorporé à la lame du microlaryngoscope (Jako Pilling Suspension microlaryngoscope). Les gaz artériels après 15 minutes (1) et 40 minutes (2) d'anesthésie donnaient les valeurs respectives suivantes: $\mathrm{Pa}_{\mathrm{CO}_{2}}=(1) 6.29 \pm 0.31 \mathrm{kPa}(47.1 \pm 2.39$ torr) et (2) $6.44 \pm 0.16 \mathrm{kPa}\left(48 \pm 1.22\right.$ torr); $\mathrm{Pa}_{\mathrm{O}_{2}}=$ (1) $29.06 \pm 4.33 \mathrm{kPa}(218 \pm 32.5$ torr) et (2) $37.06 \pm$ $4.82 \mathrm{kPa}(278 \pm 36.2$ torr). Lexposition de larynx était bonne, ce qui contribuait à raccourcir le temps chirurgical. On a relevé un taux minime de complications périopératoires, ces complications étant relevées dans 94 des 1922 anesthésies (4.89 pour cent du total). 